\title{
Time Integration Damage Model for Sn3.5Ag Solder Interconnect in Power Electronic Module
}

\author{
Pushpa Rajaguru, Hua Lu, Member IEEE and Chris Bailey, Member IEEE
}

\begin{abstract}
In this study, existing damage evolution models in the literature for solder layer in microelectronics have been reviewed. A two dimensional approximate semi-analytic time integration damage indicator model for $\mathrm{Sn3.5Ag}$ material solder interconnect in power electronic module has been proposed. The proposed time dependent damage model is dependent on the inelastic strain, the accumulated damage at previous time step and the temperature. The strains were approximated semi-analytically. A numerical modelling methodology combined with the data from public domain for crack initiation and crack propagation of $\mathrm{Sn3.5Ag}$ solder layer has been adopted to extract the parameter values of the proposed damage model. The proposed model has advantages over fatigue lifetime models as it instantaneously predicts the damage over time for any loading history. The damage model was compared with Ansys FEA tool based damage prediction using Coffin Manson and Paris law fatigue models. The predicted damage value by the model is slightly higher than those models. Furthermore, this damage model does not need a time consuming numerical simulation evaluating the damage model variables, which is an advantage
\end{abstract}

Index Terms - damage, fatigue, solder interconnect, power electronic module

\section{INTRODUCTION}

Power electronic modules (PEM) are self-contained devices widely used in various applications such as aerospace, automotive, renewable energy and energy distribution. They play a crucial role in the conversion, control and transmission of electrical power. PEM structure consists of various materials (semiconductor, ceramic, copper substrate, aluminum wire, etc.), hence they are highly homologous. Although many failure mechanisms in PEM devices were widely reported in the literature [1], solder interconnect failure is the crucial failure. PEM devices operate in harsh environment such as car engine compartment, hence fluctuating temperature in the operating environment causes thermal mismatch between various materials, which induces thermo-mechanical stresses in each layers. Solder interconnects in power module applications are relatively very thin and they are sandwiched between rigid materials such as copper substrate and silicon die. Thermo-mechanical stresses will lead to gradual increase of damage in solder interconnect and eventually this damage accumulation passed beyond a critical value will lead to electrical failure of the PEM device. In current trend, the PEM devices become smaller in spatial profile and its current handling capacity increases, solder interconnect failure become more critical to the overall reliability of the PEM device.

An accurate reliability estimation of solder interconnect depends on accurate modelling of the thermo- mechanical characteristics of the particular solder material. Solder interconnect is mechanically soft and often exposed to high temperature fluctuations hence, the plasticity and creep are dominant deformation mechanisms which cause low cycle fatigue failure. Creep damage of solder interconnect is a process of formation and growth of voids and cavities within the solder microstructure. It becomes significant when the environment temperature reaches above $0.4 \mathrm{~T}_{\mathrm{m}}$ (melting temperature of solder) [2]. The deformation of the solder layer is complicated because of the solder layer microstructures and its instability during a temperature fluctuation.

In the earlier study, a time integrated one dimensional semi-analytical approximate damage model for solder interconnect was developed which can be utilised to predict the accumulated damage at any time instant [3]. The developed damage model is most suited to $\mathrm{Sn} 3.5 \mathrm{Ag}$ material type in power electronic modules (PEM). The time based damage model has significant advantages over existing physics of failure (PoF) models, since it can represent the impact of time dependent temperature and other rate sensitive processes on solder degradation. This study improves the earlier model developed by the authors [3].

\section{OVERVIEW OF EXISTING DAMAGE MODELS}

Two commonly used fatigue lifetime prediction models in the literature are (1) models that use damage per cyclic loading to predict number of cycles to the lifetime, and (2) models that predict continuous damage accumulation for any loading profile over a period of time. The former model can normally be used for regular cyclic loading only. The 
latter model is based on damage mechanics. It predicts damage as a function of time. In damage mechanics based models, a damage parameter $D$ is used as a metric to describe the extent of damage in the structure over time. $D$ is a continuous scaler variable that varies from 0 , when there is no damage, to 1 , when complete failure occurs. The advantages of damage-based models over lifetime-based models for cyclic loading are that they can predict the process of fatigue damage for arbitrary loading profiles and hence predict lifetime in the time domain. For example, Lu et al [4] applied a damage mechanics method to predict crack propagation in IGBT solder joints. By tracking damage evolution in solder joints, crack propagation path and rates can be calculated.

Fatigue lifetime models that are used to predict the number of cycles to failure for regular cyclic loadings have a power law relationship that relates lifetime (cycles to failure) to damage metrics such as the deformation range, inelastic strain, and/or plastic work density. To use these models, the damage metric values for one temperature cycle need to be calculated [5]. For irregular cyclic loading conditions, a widely used technique for predicting lifetime is to use a cycle counting algorithm to sort irregular loading profiles into cycles with different loading amplitude and then use a fatigue lifetime model for regular cyclic loading and the Miners' linear damage accumulation rule to predict the damage accumulation in the solder layer. This includes the Rainflow cycle counting method [6] for cycle counting, and then the Coffin Mason or other nonlinear fatigue models [7] can then be used for calculating lifetime under fixed amplitude cyclic loading conditions. An application of this methodology for SnAg solder joint crack development and propagation process was demonstrated by Kostandyan et al [8] for PEM devices. This method is useful for irregular loading but it cannot predict lifetime in the time domain and the model method does not capture the effects of loading rate changes over time, nor can it take into account the changes in material properties as damage accumulates. Hence damage-based models that can capture these changes are required for predicting the reliability of PEM devices when subjected to real environmental temperature loadings.

As highlighted above, damage mechanics based modes are functions of material behavior (accumulated creep strain, plastic work density, etc.). For example a damage-based model using a thermo-dynamic framework for $\mathrm{Pb} 37 \mathrm{Sn}$ solder was proposed by Basaran et al [9]:

$$
D=1-e^{\left(-c_{1}\left(\varepsilon_{a c c}\right)^{c_{2}}\right)}
$$

where $c_{1}$ and $c_{2}$ are constants and $\varepsilon_{\text {acc }}$ is the accumulated total strain. The model is damage mechanics based but it was only validated for cyclic thermo-mechanical loading using experimental results. A damage model which utilised a creep- plasticity constitutive equation to capture the behaviour of $\mathrm{SnAg}$ solder was proposed by Stolkarts et al [10]. Stolkarts damage model is defined in equation (2)

$$
D=1-\left[1-(k+1) \int_{0}^{t} f d t\right]^{\frac{1}{k+1}}
$$

where $\mathrm{k}$ is a material constant, $f$ is a function of stress, strain and their time derivatives. This damage model can handle the loading with and without dwell times and incorporates various thermal cycling dwell times and ramp rates. For leaded solders such as $\mathrm{SnPb}$ the value of $\mathrm{k}$ is 2 [10].

For thermo-mechanical cyclic behaviour the Lemaitre's creep fatigue model [11], is most widely used. Based on the Lemaitre's creep model, a new continuum damage model was proposed by Xiao et al [12]:

$$
D=1-\left(1-D_{0}\right)\left(1-\frac{N}{N_{f}}\right)^{k}
$$

where $k$ is the damage exponent which corresponds to the damage evolution rate. $N_{f}$ is the number of cycle at failure, $D_{0}$ is the initial value of the damage. The parameters of Xiao's damage model were determined by strain measured from the thermo-mechanical cycling experiments. For $\mathrm{SnAgCu}$ solder, Xiao's damage model parameters $N_{f}$ and $k$ were 3876 and 0.154 respectively [13]. For other

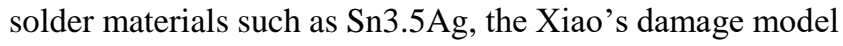
parameter values $k$ and $N_{f}$ are not available in the literature.

Wen et al [14] proposed another continuum based damage model which includes the McDowell creep plasticity constitutive equation for lead free solders. Wen's damage model is defined as a function of the physical damage metric $\omega$ and it holds a power law relationship with the damage metric $\omega$ such in equation (4) $D(\omega)=D_{e}\left(\frac{\omega}{\omega_{c}}\right)^{\eta}$

where the parameter $D_{e}$ is the critical damage parameter, and $\eta$ is the mechanical characteristic of the damaged solder layer. The damage metric $\omega$ is a function of the number of cycles at which, crack initiate and $\omega_{c}$ is the function of the limit value of number of cycles at which point solder layer is structurally damaged.

Towashiraporn et al [15] proposed a continuum damage model for solder layer under cyclic isothermal mechanical and anisothermal loadings. The damage model in their work was defined in equation (5)

$$
D(\omega)=1-\left[1+\left(\frac{\xi_{D}}{\xi_{c}}\right)^{\beta}\right]^{-\gamma}
$$

where $\xi_{c}, \beta$ and $\gamma$ are material constants and $\xi_{D}$ is the equivalent inelastic strain. Using the critical damage value (0.85) for $\mathrm{SnPb}$ solder layer, crack advancement was predicted by extrapolating the damage variable using Taylor expansion. Towashiraporn model parameters are not available for lead free solders in the literature

A damage model, which incorporates the cohesive zone constitutive model was introduced by Schreurs et al [16]. The cohesive zone model is a numerical approach to model the crack initiation and propagation [17]. The damage evolution rate in Schreurs's damage model is defined in equation (6)

$\frac{\partial D\left(t_{j}\right)}{\partial t}=c|\dot{\Delta}|\left(1-D\left(t_{j-1}\right)+r\right)^{m}\left[\frac{\left|k\left(1-D\left(t_{j-1}\right)\right) \Delta\right|}{\left(1-D\left(t_{j-1}\right)\right)}-\sigma\right]$

where $k$ is the initial stiffness of the cohesive zone, $D\left(t_{j}\right.$ $1)$ is the previous damage, $c, r$ and $m$ are constants, $\Delta$ is the relative opening of the cohesive zone and $\sigma$ is the cohesive zone endurance limit. The Schreurs's damage model is supplemented with an evolution law to account the gradual 
degradation of the solder material and the resultant accumulation of damage during a mechanical cyclic process.

Tang \& Basaran [18] proposed a continuum damage evolution model which is defined as in equation (7)

$$
D=1-e^{-\Delta e-\left(\frac{\Delta \phi k T}{N_{0} m_{0}}\right)}
$$

where $\Delta e$ and $\Delta \varphi$, are increments of internal energy and free energy respectively, $N_{0}$ - the Avogadro's constant, k Boltzmann constant, $m_{0}-$ average molecule quantity/mol, and T- absolute temperature. The Tang's damage model developed was for $\mathrm{PbSn}$ lead free solder joints. The parameter values of Tang's damage model also need to be evaluated for other solder types.

Damage mechanics based models often rely on Finite Element Analysis to predict material behavior, which makes it very time-consuming. Yang et al [19] proposed a time integration damage model for aluminum wirebond in PEM devices. It is a semi-empirical method but cannot be applied to solder interconnects, since the material characteristics of aluminum wirebond are different to solder interconnects. Furthermore the mechanical and material properties of solder material change over time as damage accumulates. The damage model proposed in this paper captures this dynamic properties of the solder material.

\section{TIME INTEGRATION DAMAGE MODEL}

In earlier study a time integration damage model for Sn3.5Ag solder was proposed. The damage model takes into account the crack initiation and propagation in the $\mathrm{Sn} 3.5 \mathrm{Ag}$ solder interconnect for an IGBT power module. The approach presented differs from traditional cycle-based lifetime models as it can predicts solder damage at any time step. Moreover time consuming FEA is not required for deformation metrics of solder interconnect in order to predict the damage.

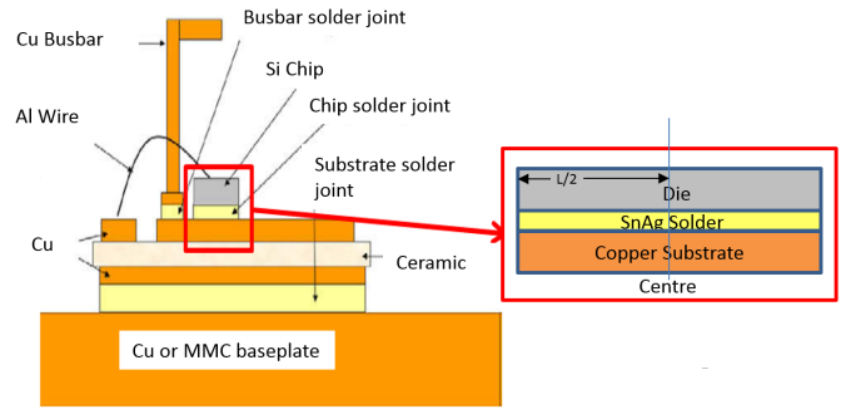

Fig. 1: Cross sectional view of the power module and 2D solder interconnect structure.

The stress and strain in the solder interconnect depend on several factors such as the temperature strain (deformation) rate and strain history [20]. The influencing factors of the proposed damage model are the damage accumulation at previous time step, temperature and strain history as functions of time. The time integration damage model assumes that total damage at any point along the interface (silicon chip/solder layer interface as detailed in Fig. 1) and can be described by the following generic equation [3]

$$
\begin{aligned}
& D\left(t_{j}\right)=D\left(t_{j-1}\right)+2 \alpha_{G} L\left|\varepsilon_{i n}\left(t_{j}\right)\right|\left[1-e^{\frac{-2 \beta_{E}\left(\frac{L}{2} l\left(t_{j}\right)\right)}{L\left|\varepsilon_{i n}\left(t_{j}\right)\right|}}\right](1+ \\
& \left.\alpha_{D} D\left(t_{j-1}\right)^{\beta_{D}}\right)\left(1+\beta_{T} T\left(t_{j}\right)\right) \frac{\partial \varepsilon_{D}}{\partial t}-2 D\left(t_{j-1}\right)\left[\frac{\Delta l\left(t_{j-1}\right)}{\Delta \mathrm{t}}\right] \Delta \mathrm{t}
\end{aligned}
$$

where $l\left(t_{j}\right)=\sum_{i=1}^{j} \Delta l\left(t_{i}\right)$, crack length increment at each time step from the edge

The crack propagates from both edges towards the centre. Crack length increment $\Delta l\left(t_{j}\right)$ rate at any time step is approximately defined as

$$
\frac{\Delta l\left(t_{j}\right)}{\Delta t} \approx \alpha_{L} D\left(t_{j-1}\right)+\beta_{L}\left(\frac{D\left(t_{j}\right)-D\left(t_{j-1}\right)}{\Delta \mathrm{t}}\right)
$$

$\frac{\partial \varepsilon_{D}}{\partial t}=\left|\alpha_{S i}-\alpha_{C u}\right|\left(T\left(t_{j}\right)-T\left(t_{j-1}\right)\right)$ - Thermally induced strain increment at each time step. $\left(1+\alpha_{D} D\left(t_{j-1}\right)^{\beta_{D}}\right)$ Damage hardening function, expressed as power law function. $1+\beta_{T} T\left(t_{j}\right)$ - Temperature hardening function and $D\left(t_{j}\right)$ is damage accumulation at time $t_{j} . \alpha_{S i}, \alpha_{C u}-$ Coefficient of thermal expansion of silicon chip and copper substrate respectively. $\varepsilon_{i n}\left(t_{j}\right)$ - Inelastic strain at time step $t_{j}$. $T\left(t_{j}\right)$ - Temperature at time step $t_{j} . L$-Solder interconnect length and $\Delta \mathrm{t}=\left(t_{j}-t_{j-1}\right)$ - Time increment. The parameters $\alpha_{G}, \beta_{E}, \alpha_{D}, \beta_{D}, \beta_{T}, \alpha_{L}, \beta_{L}$, are the damage model (equation (8)) coefficients, which need to be evaluated from experimental data for particular solder material. This reduces the contents to steps as

- Step 1: Evaluate the damage model stress and strain values. Section (IV) describe the stress and strain evaluation of the damage model

- Step 2: Estimate the damage model coefficients. Section (V) describes the methodology to evaluate the coefficients.

- Step 3: Predict the damage over a time scale and compare. Section (VI) discuss the comparison of the damage model with other fatigue models

\section{STRESS AND STRAIN EVALUATION}

One of the challenging aspects in practical applicability of the damage model (Equation (8)) is the estimation of the inelastic strain value. Generally a numerical simulation (FEA) or an experiment is required to estimate the inelastic strain value. A practical semi empirical method to estimate the thermally induced accumulated inelastic strain in the solder layer of the assembly is outlined in this section. A number of analytical models exist in the literature for predicting the normal (peeling) stress and shear stresses of the tri-layer assembly consisting the layers of IC package, adhesive, and PCB board. Suhir's approach considers the tri-layer assembly as a thin sandwiched layers and then 
estimate the solder layer shear and peel stresses [21, 22]. Suhir's analytical model assumes that the thickness of the die attach (solder) layer is thin compared to the thickness of die and PCB board. For a thick layer of solder a beam analysis model was proposed by Wong et al [23, 24]. For the case of solder layer in IGBT structure Suhir's analytical model was utilised. An assumption is made such that Suhir's model is valid for Power electronic structures.

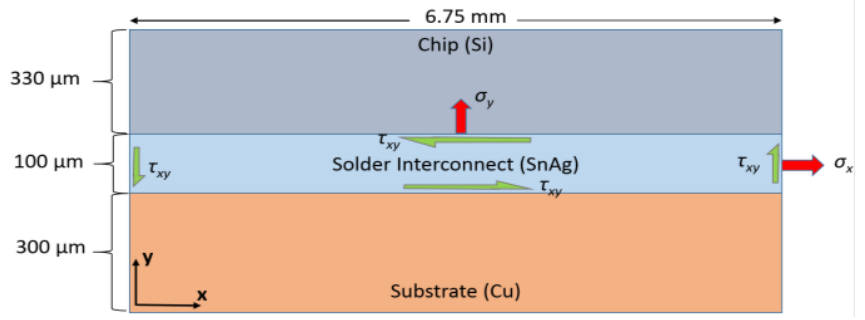

Fig. 2: shear and normal stresses in 2D solder interconnect structure with dimensional data of $\mathrm{Lu}$ et al [25].

In Suhir's model, the Shear stress on the solder layer along the $\mathrm{x}$ axis is defined as $\tau(\mathrm{x})$

$$
\tau(\mathrm{x})=\frac{\mathrm{k}\left(\alpha_{3}-\alpha_{1}\right) \Delta \mathrm{T}}{\lambda \operatorname{Cosh}(\mathrm{kL})} \operatorname{Sinh}(\mathrm{kx})
$$

where $\mathrm{k}=\sqrt{\frac{\lambda}{\kappa}}$, is the longitudinal compliance, $\lambda=$

$$
\frac{1-v_{1}}{E_{1} h_{1}}+\frac{1-v_{3}}{E_{3} h_{3}}+\frac{h}{4 D}, \kappa=\frac{h_{1}}{3 G_{1}}+\frac{2 h_{2}}{3 G_{2}}+\frac{h_{3}}{3 G_{3}}, G_{i}=\frac{E_{i}}{2\left(1+v_{i}\right)},
$$$$
D_{i}=\frac{E_{i} h_{i}{ }^{3}}{12\left(1-v_{i}{ }^{2}\right)}, h=h_{1}+h_{2}+h_{3}, D=D_{1}+D_{2}+D_{3}
$$

$D_{i}, E_{i}, G_{i}, v_{i}, h_{i}, \alpha_{i}$ are respectively flexural rigidity, Young's modulus, shear modulus, Poisson's ratio, thickness and coefficient of thermal expansion (CTE) of the layer $i$. Layer $i=1,2$, and 3 represent the chip, solder and copper substrate layers respectively. Peeling stress (transverse) on the solder layer along the $x$ - axis is defined as $\sigma_{y}(x)$ (see Tsai et al [22])

$$
\begin{gathered}
\sigma_{y}(\mathrm{x})=\frac{\mu\left(\alpha_{3}-\alpha_{1}\right) \Delta \mathrm{T}}{\mathrm{\kappa}} \frac{s^{4}}{1+s^{4}}\left[\mathrm{~A}_{0} \mathrm{~V}_{0}(\beta x)+\mathrm{A}_{2} \mathrm{~V}_{2}(\beta x)+\frac{\operatorname{Cosh} \mathrm{kx}}{\operatorname{Cosh} \mathrm{kl}}\right] \\
\text { where, } \mu=\frac{h_{3} D_{1}-h_{1} D_{3}}{2 D}, s=\frac{\beta \sqrt{2}}{k}, \beta=\sqrt[4]{\frac{K D}{4 D_{1} D_{3}}} \\
K=\left[\frac{\left(1-v_{1}\right) h_{1}}{E_{1}}+\frac{\left(1-v_{3}\right) h_{3}}{E_{3}}\right]^{-1} \\
\mathrm{~A}_{2}=2 \sqrt{2} \frac{V_{1}(\beta l)-s^{3} V_{2}(\beta l) \tanh (k l)}{\mathrm{s}^{2}(\sinh (2 \beta l)+\sin (2 \beta l))} \\
V_{0}(\beta l)=\cosh (\beta l) \cos (\beta l), V_{2}(\beta l)=\sinh (\beta l) \sin (\beta l) \\
V_{1}(\beta l)=\frac{1}{\sqrt{2}}(\cosh (\beta l) \sin (\beta l)+\sinh (\beta l) \cos (\beta l)) \\
V_{3}(\beta l)=\frac{1}{\sqrt{2}}(\cosh (\beta l) \sin (\beta l)-\sinh (\beta l) \cos (\beta l))
\end{gathered}
$$

The melting temperature $\left(\mathrm{T}_{\mathrm{m}}\right)$ of $\mathrm{Sn} 3.5 \mathrm{Ag}$ solder is $221^{\circ} \mathrm{C}$ [26]. Since solder material have high homologous temperature, they often undergo creep deformation in their operating environment, and this is their primary deformation behaviour. A unified creep and plasticity strain (inelastic) constitutive equation is utilised. To evaluate the inelastic strain in solder interconnect, which is a variable in the damage function (equation (8)), an inelastic constitutive model was employed. Anand constitutive equation for viscoplastic strain rate is defined as in equation (13)

$$
\dot{\varepsilon}_{V i s c o}=A e^{\frac{-Q}{R T}}\left[\sinh \left(\xi \frac{\sigma}{s}\right)\right]^{(1 / m)}
$$

TABLE 1: THE VALUES OF ANAND MODEL COEFFICIENTS FOR EQUATION (13) [27, 28]

\begin{tabular}{ll}
\hline \multicolumn{1}{c}{ Anand Parameters } & Value \\
$\boldsymbol{A}\left(\mathbf{s e c}^{-1}\right)$ & $2.23\left(10^{4}\right)$ \\
$\boldsymbol{Q} / \boldsymbol{R}\left({ }^{\circ} \mathbf{k}\right)$ & 8900 \\
$\boldsymbol{\xi}$ & 6 \\
$\boldsymbol{m}$ & 0.182 \\
$\hat{\boldsymbol{s}}(\mathbf{M P a})$ & 73.81 \\
$\boldsymbol{n}$ & 0.018 \\
$\boldsymbol{h}_{\boldsymbol{0}}(\mathbf{M P a})$ & 3321.15 \\
$\boldsymbol{a}$ & 1.82 \\
$\boldsymbol{s} \boldsymbol{0}(\mathbf{M P a})$ & 39.09 \\
\hline
\end{tabular}

\section{A. Stress Relaxation due to Creep}

Stress relaxation is a time dependent deformation process of solder material under constant loading. Solder material under constant strain will experience a stress decrement/ relaxation. Contrarily, if the stress in the solder material is held constant then the strain in the solder material will increase with time due to creep [29]. Several studies on solder material stress relaxation due to creep were reported in the literature [30-32]. Stress relaxation due to creep in this analysis is based on the report by Anand et al [33, 34]. In a 2 dimensional tri-layer structure, the Cauchy stress tensor $T_{j+1}^{*}$ in this solder interconnect layer is defined as:

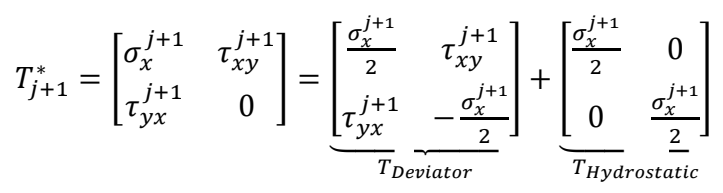

The deviatoric stress tensor $\left(T_{\text {Deviator }}\right)$ can be extracted by subtracting the hydrostatic stress tensor $\left(T_{\text {Hydrostatic }}\right)$ from Cauchy stress tensor. Then the initial value of equivalent stress, $\sigma_{n+1}^{*}$, can be calculated, which is defined as

$$
\sigma_{j+1}^{*}=\sqrt{\frac{3}{2}}\left\|T_{\text {Deviator }}\right\|
$$

Then the internal variable $s_{j+l}$ and equivalent stress $\tilde{\sigma}_{n+1}$ are calculated by solving the nonlinear system of equations ((16) and (17)).

$$
\begin{aligned}
& s_{j+1}-s_{j}-\Delta t \dot{s}\left(\tilde{\sigma}_{j+1}, s_{j+1}\right)=0 \\
& \tilde{\sigma}_{j+1}-\sigma_{j+1}^{*}+3 \mu \Delta t \dot{\varepsilon}_{\text {Visco }}\left(\tilde{\sigma}_{j+1}, s_{j+1}\right)=0
\end{aligned}
$$


where $\mu=\frac{E}{2(1+v)}$, is elastic shear moduli, $\dot{\varepsilon}_{V i s c o}\left(\tilde{\sigma}_{j+1}, s_{j+1}\right)$ is viscoplastic strain rate defined as in equation (13) and $\dot{s}\left(\tilde{\sigma}_{j+1}, s_{j+1}\right)$ rate of change of internal variable. 'Fsolve' function in a GNE Octave [35] code was utilised to approximate two unknowns in two nonlinear system of equations (16) and (17). $s_{j}$ is internal variable value at the time $t_{j}$. Then the stress tensor is updated as in equation (18)

$$
\begin{gathered}
T_{j+1}=\left(\frac{\widetilde{\sigma}_{j+1}}{\sigma_{j+1}^{*}}\right) T_{\text {Deviator }}+T_{\text {Hydrostatic }} \\
\varepsilon_{\text {Visco }}\left(\tilde{\sigma}_{j+1}, s_{j+1}\right)=\varepsilon_{\text {Visco }}\left(\tilde{\sigma}_{j}, s_{j}\right)+ \\
\dot{\varepsilon}_{\text {Visco }}^{i}\left(\tilde{\sigma}_{j+1}, s_{j+1}\right)
\end{gathered}
$$

Plastic strain tensor $\boldsymbol{\varepsilon}_{n+1}^{P}$ is defined as

$$
\varepsilon_{j+1}^{P}=\frac{3}{2} \varepsilon_{V i s c o}\left(\tilde{\sigma}_{j+1}, s_{j+1}\right)\left(\frac{T_{j+1}}{\widetilde{\sigma}_{j+1}}\right)
$$

\section{B. Stress comparison with Ansys Stress}

In order to validate the stresses and strains generated in Section (IV), a stress prediction was compared with an Ansys finite element model. Dimensional details of the 2D chip solder substrate tri-layer assembly in a PEM device is as in Fig. 2. An FEA model was generated and simulated in Ansys Parametric Design Language (APDL). The material properties adopted in FEA is listed in the Table 2. Structural boundary condition applied in the FEA model is as in Fig. 3(a).

TABLE 2: MATERIAL PROPERTIES USED IN ANSYS MODELLING AND IN DAMAGE MODEL

\begin{tabular}{lllll}
\hline Material & $\begin{array}{l}\text { Young's } \\
\text { Modulus } \\
(\mathrm{GPa})\end{array}$ & $\begin{array}{l}\text { Poisso } \\
\mathrm{n} \text { Ratio }\end{array}$ & $\begin{array}{l}\text { Coefficient of } \\
\text { Thermal } \\
\text { Expansion } \\
\left(10^{-6} / \mathrm{K}\right)\end{array}$ & $\begin{array}{l}\text { Density } \\
\left(\mathrm{Kg} / \mathrm{m}^{3}\right)\end{array}$ \\
$\begin{array}{l}\text { Chip }(\mathrm{Si}) \\
\begin{array}{l}\text { Solder } \\
(\mathrm{Sn} 3.5 \mathrm{Ag})\end{array}\end{array}$ & $\begin{array}{l}54.05- \\
0.193 * \mathrm{~T}\left({ }^{\circ} \mathrm{C}\right)\end{array}$ & 0.4 & $\begin{array}{l}21.85+0.0239 \\
* \mathrm{~T}\left({ }^{\circ} \mathrm{C}\right)\end{array}$ & 7360 \\
$\begin{array}{l}\text { Substrate } \\
(\mathrm{Cu})\end{array}$ & 115 & 0.31 & 17.3 & 8960 \\
& & & & \\
\end{tabular}

(a)

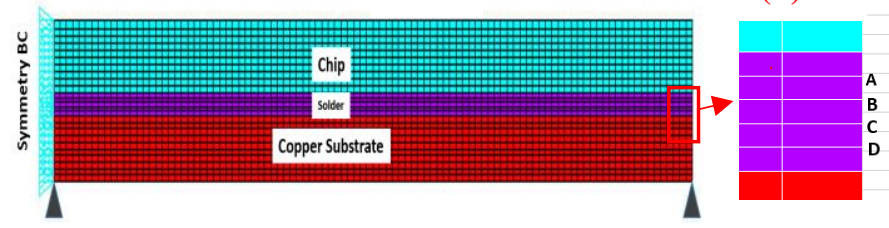

Fig 3: (a) Structural boundary condition imposed on 2D model in Ansys, (b) The nodes label in solders layers

Thermal cyclic loading imposed on the model is Ramp time $=180 \mathrm{~s}$, Dwell time $=900 \mathrm{~s}$, Maximum temperature $=$ $125^{\circ} \mathrm{C}$, and Minimum temperature $=-25^{\circ} \mathrm{C}$. The predicted value of shear stress by the proposed damage model closely matches with the predicted values by the Ansys FEA simulation at various nodes (as in Figure 3(b)). Fig 4 illustrate the plots of shear stress value by damage model and shear stress by Ansys FEA predictions at various nodes. The peel stress values by damage model is slightly underestimating in comparison with the values predicted by the Ansys simulation.

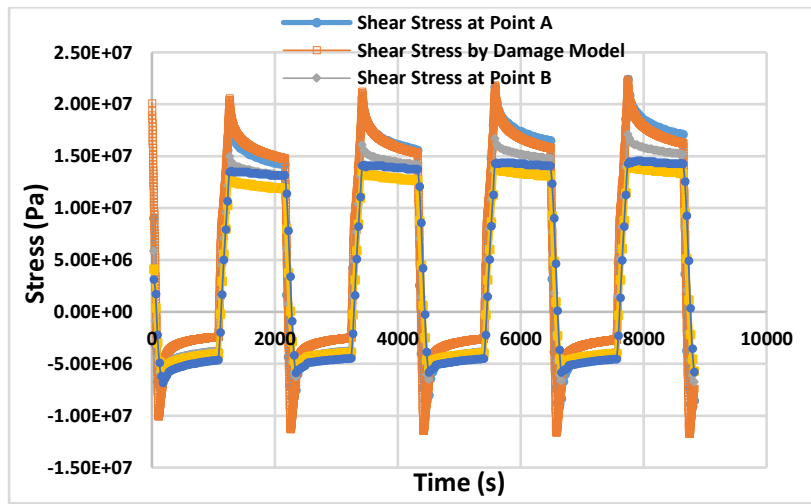

Fig. 4: Shear stress component of stress tensor (Equation (20) from damage model and Ansys modelling shear stresses at nodes A, B, C, and D (Figure 3(b)) .

\section{Estimating DAMAGE MODEL PARAMETERS}

Ideally an experimental data is required to evaluate the coefficient values for crack length prediction such as $\alpha L, \beta L$ and coefficients of the time integration damage model such as $\alpha_{G}, \beta_{E}, \alpha_{D}, \beta_{D}, \beta_{T}$ for Sn3.5Ag solder material profile. A limited experimental data of $\mathrm{Sn} 3.5 \mathrm{Ag}$ solder material from public domain was utilised to approximate the coefficients values of the damage model in equation (8). Darveaux et al [36] data consists of Sn3.5Ag solder fatigue crack initiation and growth rate in wafer level chip scale packages (WLCSP) for four temperature profiles. An assumption was made such that, the Darveaux data is valid for solder layer in the PEM devices as well. Furthermore, crack growth rate per cycle is constant as cycle progresses.

A 3D model with Darveaux dimensional data as in Fig 5, was simulated in Ansys in order to extract the accumulated inelastic strain for each temperature cycle profile. A three point structural boundary condition was imposed on the model for mimicking the structural constraint. For each temperature cycling profile, accumulated average inelastic strain and strain energy per cycle were extracted from 3D finite element model and these data is listed in the Table 3. From the ratio of the solder bump interconnect length in WLCSP and mean value of crack growth rate ( $\mu \mathrm{m} /$ Cycle), damage percentage $(\%)$ per cycle were derived for each temperature cycle profile and listed on the Table 3 


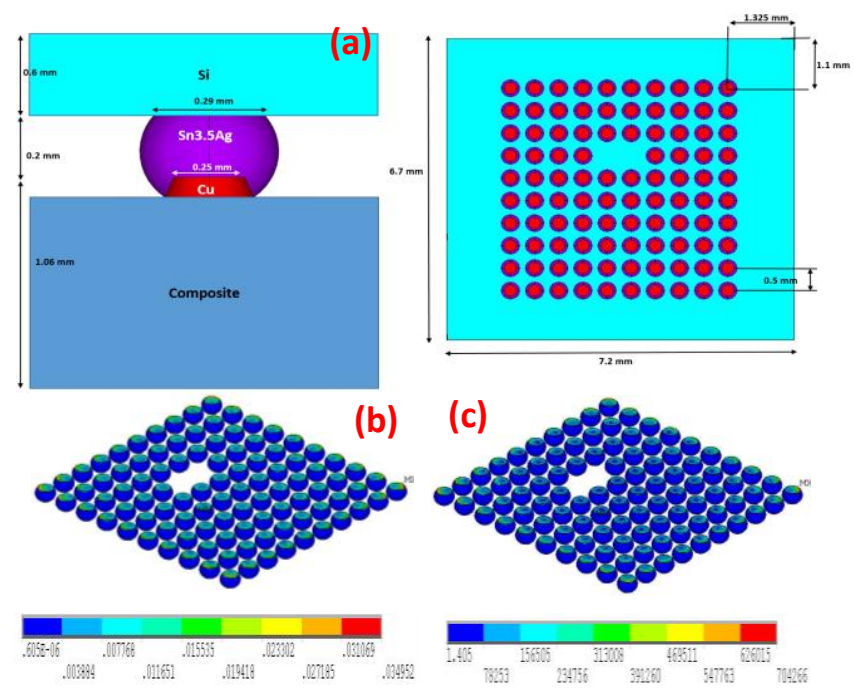

Fig. 5: (a) Darveaux et al [36] test board schematic and dimensions. (b) Accumulated inelastic strain distribution in solder bumps for one cycle, (c) Accumulated strain energy $(\mathrm{J} / \mathrm{m} 3)$ distribution in solder bumps for one cycle

With known damage percentage value and accumulated inelastic strain values in one cycle, a nonlinear least square method ('Isqnonlin' function) was utilised in OCTAVE to extract the damage model (Equation (8)) coefficients. With four nonlinear equations for five unknown coefficients, by setting one coefficient value $\left(\beta_{\mathbf{D}}\right)$ as 1 , the value of the other coefficients were extracted. The damage model coefficient values are listed in the Table 4.

TABLE 3: ACCUMULATED PLASTIC STRAIN, STRAIN ENERGY, DAMAGE PERCENTAGE PER CYCLE FOR EACH TEMPERATURE PROFILE FROM ANSYS 3D SIMULATION

\begin{tabular}{cccc}
\hline Cycle & $\begin{array}{l}\text { Accumulated } \\
\text { Plastic Strain }(\times \\
\left.10^{-2}\right)\end{array}$ & $\begin{array}{l}\text { Accumulated } \\
\text { plastic Work } \\
\left.\left(\mathrm{MJ} / \mathrm{m}^{3}\right)\right)\end{array}$ & $\begin{array}{l}\text { Damage } \\
\text { Percentage per } \\
\text { Cycle } \\
(\%)\end{array}$ \\
A & 6.58 & 2.25 & 0.09021 \\
B & 3.32 & 0.81 & 0.03131 \\
C & 2.48 & 0.41 & 0.01152 \\
D & 1.34 & 0.22 & 0.00232 \\
\hline
\end{tabular}

TABLE 4: ESTIMATED DAMAGE INDICATOR MODEL (EQUATION (8)) COEFFICIENTS.

\begin{tabular}{cccccc}
\hline Coefficient & $\boldsymbol{\alpha}_{\mathbf{G}}$ & $\boldsymbol{\beta}_{\mathbf{E}}$ & $\boldsymbol{\alpha}_{\mathbf{D}}$ & $\boldsymbol{\beta}_{\mathbf{D}}$ & $\boldsymbol{\beta}_{\mathbf{T}}$ \\
Value & 0.15 & 70.048 & 0.421 & 1 & 94.908 \\
\hline
\end{tabular}

Crack start to initiate after the damage reached a threshold value $\left(D_{\text {Threshold }}\right)$. At present $\mathrm{D}_{\text {Threshold }}$ is assumed as zero. The crack initiates instantly as damage start to accumulate.

\section{COMPARISION AND DISCUSSION}

\section{A. Time Advantage}

The time consumption by the damage model for one cycle was approximately 64 seconds. In contrast time taken by Ansys for plastic FEA analysis was approximately 1758 seconds. In both cases time step was fixed as 1 second. Furthermore Ansys simulation required additional times for model building, physics and boundary condition set up and for post processing the results. Hence Damage model methodology has clear advantage in terms of time efficiency and in practical engineering applicability.

\section{B. Damage Model Comparison with Ansys Damage Prediction}

The damage model (Section (III)) which was implemented in OCTAVE was employed for predicting the damage accumulation numerically for a temperature cyclic load. The damage model was compared with damage prediction by Ansys simulation deformation data and the fatigue models. Empirical solder joint Coffin Manson fatigue model for Sn3.5Ag to predict the reliability was reported by Beijer et al [37]. Similarly the Englemaier fatigue model for Sn3.5Ag solder was reported by Chauhan et al [38]. According to Beijer et al, the number of cycle to failure $N_{f}$ for SnAg has been defined as in equation (22)

$$
N_{f}=6038\left(\Delta W^{\text {ave }}\right)^{-1.45}
$$

Lu et al $[39,40]$ defined a crack propagation fatigue model for SnAg solder layer in a PEM device by incorporating Paris law (equation (22))

$$
a\left(\Delta \varepsilon_{i n}\right)^{b}=\frac{L}{N_{L}}
$$

where $L$ is the solder interconnect length in millimetres, $a$, $b$, are constants taking the values of 0.00562 and 1.023 respectively, $N_{L}$ is the required number of cycles for the crack to reach the length $L$ in millimetre and $\Delta \varepsilon_{i n}$ average accumulated inelastic strain per one cycle.

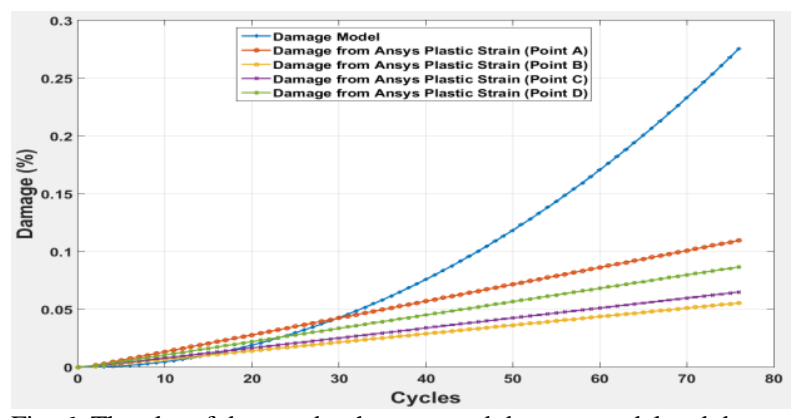

Fig. 6: The plot of damage by the proposed damage model and damage derived from Lu's fatigue data and Ansys accumulated inelastic strain values at points A-D

From the Ansys simulation for 2D structure as in Fig 3 (Section (IV)) equivalent plastic strain and plastic strain energy per cycle were extracted at four nodal points (A-D). These extracted strain and strain energy values were inserted into Beijer and Lu's fatigue models (Equations (21) and (22)) to predict the damage percentage. The comparison of damage prediction by the proposed damage model versus Ansys based damage at the nodal points A-D with Lu's fatigue data for up to 75 cycles is in Fig. 6. Similarly Fig. 7, illustrate the plot of damage by damage model versus damage derived from Ansys strain energy at locations A-D with Beijer's fatigue data. 


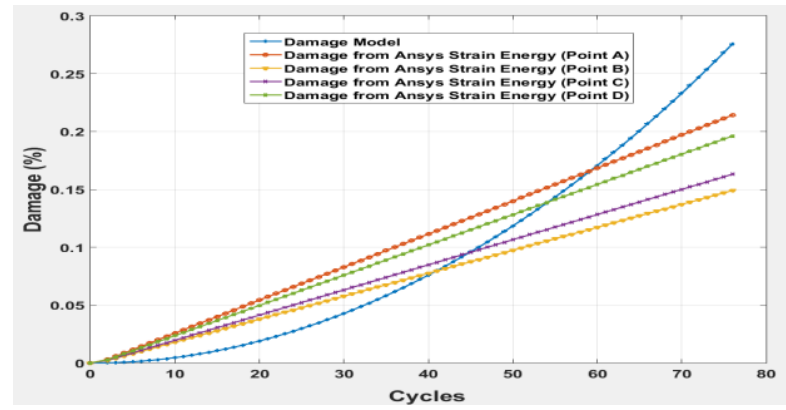

Fig. 7: The plot of damage by the damage model and damage derived from Beijer's fatigue model and Ansys accumulated inelastic strain energy values at points A-D.

The plots of crack length $(\mu \mathrm{m})$ versus time (s) and damage (\%) versus time (s) are presented in Fig. 8. Shear stress versus shear inelastic strain plot generated from the damage model is in Fig. 9. Similarly normal stress versus inelastic strain plot is in Fig. 10. The damage prediction by damage model is slightly over predicting in comparison with damage based on Ansys strain/energy and Beijer's and Lu's coefficients as cycle progresses because of

- Proposed damage model is nonlinear in contrast to linear damage prediction by the fatigue based damage data such as Lu's Paris law

- Proposed damage model is a function of previous damage, hence damage accumulate exponentially as time progresses.

Nevertheless, unlike fatigue model based damage the damage model proposed in this study can predict the damage at any time instance for any arbitrary thermal load. Moreover, the damage model doesn't require time consuming FEA simulation for estimating the deformation metrics in order to evaluate the damage, hence it is efficient.

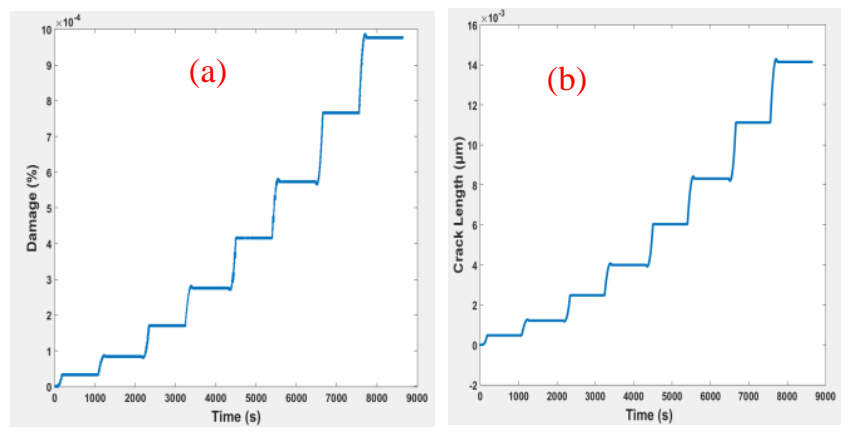

Fig. 8: (a) Damage (\%) versus time (s) by the damage model (Equation (8)), (b) Crack length versus cycles for the cyclic thermal load profile

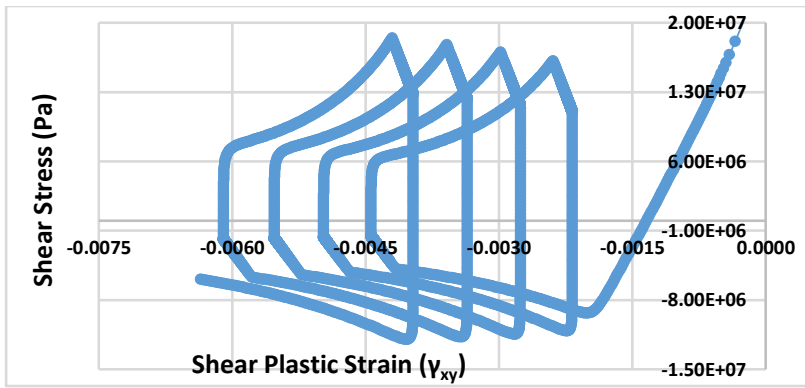

Fig. 9: Shear stress versus shear inelastic strain plot by damage model (Equation 8)

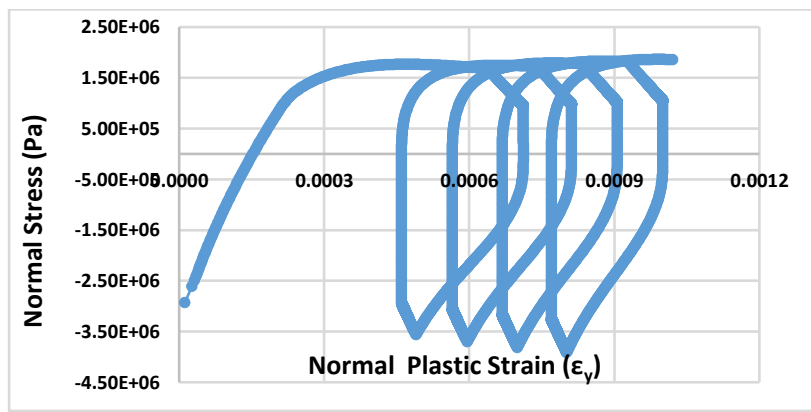

Fig. 10: Normal stress versus normal inelastic strain by damage model (Equation (8))

\section{Irregular Loading}

In this section, a demonstration of damage model prediction for an irregular thermal load (as in Fig 11) on the structure is presented.

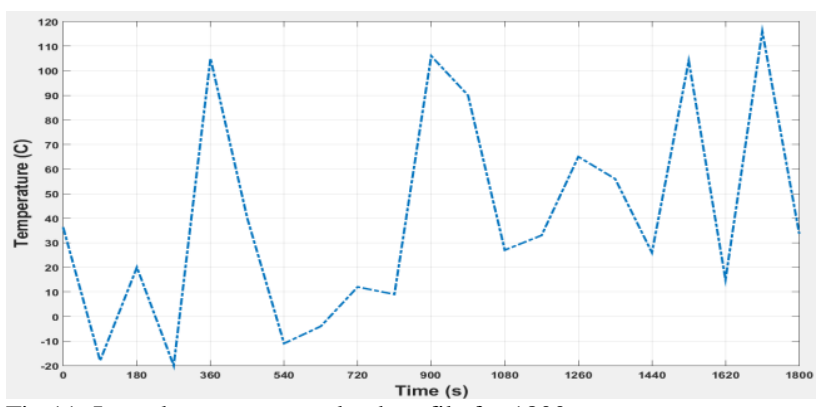

Fig.11: Irregular temperature load profile for $1800 \mathrm{~s}$

The stress versus inelastic strain plots generated from the methodology discussed in Section (IV) for shear and normal components under the irregular temperature loading (Fig. 11) are in the Fig. 12 (a) and (b). The damage model prediction for the irregular loading profile was correlated with Ansys damage prediction by Lu's fatigue data. Since fatigue models can be only applicable for cyclic loading, a Rainflow cycle counting algorithm was applied to extract the cycles. The counted cycle data for the temperature profile (Fig. 11) is in Fig. 13. 
(a)

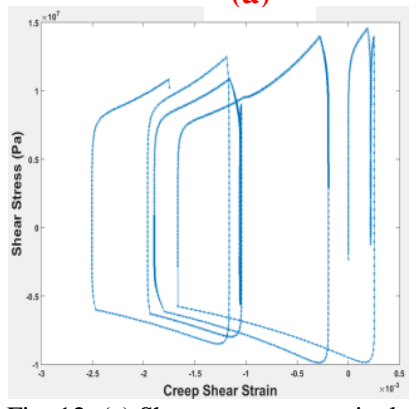

(b)

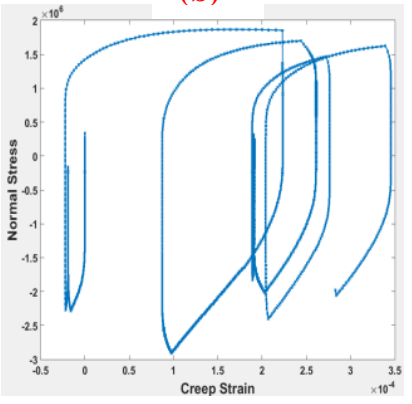

Fig. 12: (a) Shear stress versus inelastic shear strain plot, (b) normal stress versus inelastic strain plot

By applying rainflow cycle counting algorithm to the irregular temperature profile, the individual temperature cycles and their associated quantities (amplitude, start time, end time, and mean temperature) are extracted. For each counted cycle profiles, accumulated inelastic strain and strain energy were extracted in Ansys 2D model. By inserting the strain into fatigue models for each counted cycles, fatigue life $\left(N_{f}\right)$ were derived. The summation of these reciprocal (Miner's rule) of the fatigue life is the total fatigue damage for irregular loading. Fig. 14 illustrate the damage model prediction for irregular thermal loading, and the damage prediction based on fatigue data, Rainflow cycle counting, Miners rule and the strain/Energy at the Points AD (Fig. 3) for 18000s (thermal profile (Fig. 11) repeated 10 times).

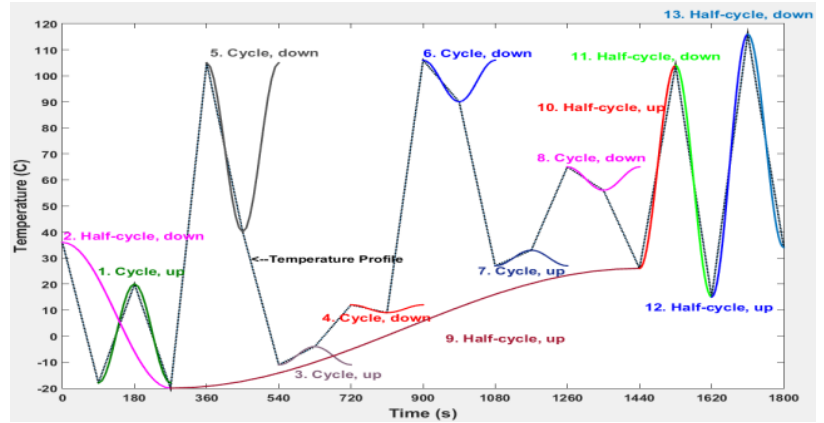

Fig.13: Plot of cycles generated by Rainflow cycle counting algorithm for the thermal load in Fig.12

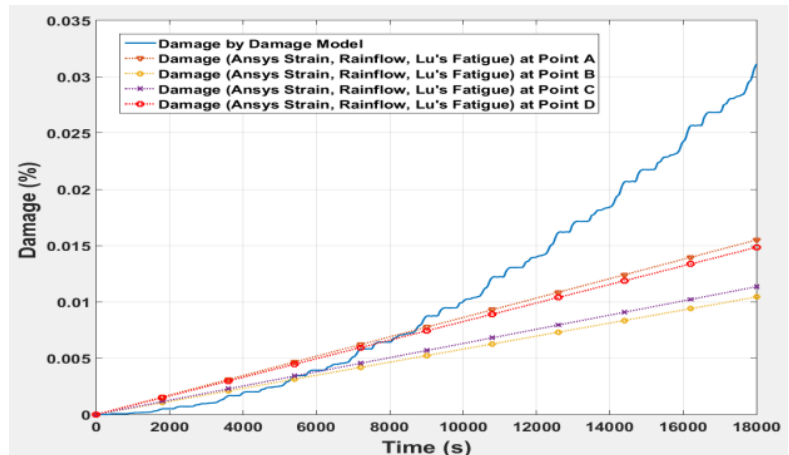

Fig. 14: Damage prediction by damage model and damage based on Lu's fatigue model, Miners rule, Rainflow cycle counting algorithm and the Ansys strain at Points A-D.

Again the damage model slightly over predict for irregular loading. Although time efficiency is advantage of this damage methodology, the drawback is it can't capture the geometrical nonlinearities of the domain. The coefficients of the damage model developed in this study still need to be accurately validated with more experimental data for $\mathrm{SnAg}$ solder material.

\section{CONCLUSION}

An improved time integration damage model for the evaluation of the instantaneous total damage of $\mathrm{Sn} 3.5 \mathrm{Ag}$ solder interconnect in PEM is proposed. The proposed model can predict the instantaneous damage at any time step in contrast to cycle based damage prediction in the literature, which is an advantage. The controlling factors of the time integration damage model are inelastic strain, displacement strain, damage history and temperature. The experimental data for crack initiation and propagation from public domain together with a finite element modelling were exploited to extract the parameter values of the damage model. A nonlinear least square algorithm for estimating the prior shear stress and inelastic strain in solder layer for an arbitrary thermal loading and resulting damage accumulation in the layer was utilised.

The developed damage model was compared with Ansys based damage prediction using fatigue models. Two case studies such as cyclic loading and irregular loading were presented for the proposed damage methodology. The damage model slightly over predicts the damage accumulation in comparison with Ansys based damage prediction. Nevertheless, this damage model doesn't require a time consuming FEA simulation for evaluating the damage model variables which is an advantage. Additionally, the damage model has significant advantage over existing damage models, since it incorporates the impact of temperature dependent material processes. Furthermore, the model can be evaluated by an open source software OCTAVE. In spite of that, damage model (equation (8)) coefficients as well as parameters for crack progression still needs to be calibrated for accurate experimental data. The model only considers 2 dimensional structure, although it can be extended to three dimensional structure.

\section{ACKNOWLEDGEMENTS}

Financial support from the Engineering and Physical Sciences Research Council (EPSRC), UK, through the Underpinning Power Electronics HUB (EP/K034804/1). It supports the 'Cross cutting topics' project: 'Design, Tools \& Modelling' is acknowledged.

\section{REFERENCES}

[1] C. Mauro, Selected failure mechanisms of modern power modules. Microelectronic Reliability, 42, pp. 653-67, 2002

[2] M. N. Tamin, N. M. Shaffiar, Solder joint reliability assessment, Finite element simulation methodology, Springer series, 2014 
[3] P. Rajaguru, H. Lu, C. Bailey, A time dependent damage indicator model for Sn3.5Ag solder layer in power electronic module, Microelectronic Reliability, 55 (11), pp 2371 - 2381, 2015

[4] H. Lu, S. Ridout, C. Bailey, W. S. Loh, A. Pearl, and M. Johnson, Computer simulation of crack propagation in power electronics module solder joints, 2008 International Conference on Electronic Packaging Technology \& High Density Packaging (ICEPT-HDP), Shanghai, China, 2008

[5] W. W. Lee, L. T. Nguyen, and G. S. Selvaduray, Solder joint fatigue models: Review and applicability to chip scale packages, Microelectronic Reliability, 40, pp. 231-244, 2000

[6] ASTM E-1049 85. Standard practices for cycle counting in fatigue analysis; 2005

[7] P. Rajaguru, H. Lu, and C. Bailey, Application of Kriging and radial basis function in power electronic module wirebond structure reliability under various amplitude loading, International Journal of Fatigue, 45, pp. 61-70, 2012

[8] E. E. Kostandyan and J. D. Sorensen, Reliability assessment of solder joints in power electronic modulus by crack damage model for wind turbines applications, Energies, 4, pp. 2236-2248, 2011

[9] C. Basaran, H. Tang and S. Nie, Experimental damage mechanics of microelectronic solder joints under fatigue loading, Mechanics of Materials, 36, pp. 1111-1121, 2004

[10] V. Stolkarts, B. Moran and L. M. Keer, Constitutive and damage model for solders, IEEE Proceedings of Electronic components and technology conference (ECTC), Seattle, USA, pp. 379-385, 1998

[11]J. Lemaitre and R. Desmorat, Engineering damage mechanics ductile, creep, fatigue and brittle failures, Springer-Verlag, Berlin, 2005

[12]H. Xiao, X. Y. Li, Y. Lu, F. Guo, and Y. W. Shi, Damage behaviour of $\mathrm{SnAgCu} / \mathrm{Cu}$ solder joints subjected to thermo-mechanical cycling, Journal of Alloys and Compounds, 578, pp. $110-117,2013$

[13]H. Xiao, X. Li, N. Liu and Y. Yan, A damage model for $\mathrm{SnAgCu}$ solder under thermal cycling, 12th International Conference on Electronic Packaging Technology \& High-density Packaging, Shanghai, China, pp. 772-776, 2011

[14] S. Wen, L. M. Keer and H. Mavoori, Constitutive and damage model for a lead free solder, Journal of Electronic Materials, 30, pp. 1190-1196, 2001

[15]P. Towashiraporn, G. Subbarayan, and C. S. Desai, A hybrid model for computationally efficient fatigue fracture simulations at microelectronic assembly interfaces, International Journal of Solids and Structures, 42, pp. 4468-4483, 2005

[16]A. A. Baqi, P. J. G. Schreurs and M. G. D. Geers, Fatigue damage modelling in solder interconnects using a cohesive zone approach, International Journal of Solids and Structures, 42, pp. 927-942, 2005, 1987 [17]A. Needleman, A continuum model for void nucleation by inclusion debonding, Journal of Applied Mechanics, 54 (3), pp. 525 - 531, 2010

[18]H. Tang and C. Basaran, A damage mechanics based fatigue life prediction model for solder joints, ASME Journal of Electronic Packaging, 125, pp. 120-125, 2003

[19]L. Yang, P. A. Agyakwa, and C. M. Johnson, Physics-of-failure lifetime prediction models for wire bond interconnects in power electronic modules, IEEE Transactions on Device and Materials Reliability, 13 ( 1), pp. 9 - 17, 2013

[20]G. E. Dieter, Mechanical Metallurgy, McGraw-Hill, Inc., Third Edition, 1986

[21]E. Suhir, An approximate analysis of stresses in multilayered elastic thin films, ASME journal of Applied Mechanics, 55 (1), 1988

[22]M. Y. Tsai, C. H. Hsu, and C. N. Han, A note on Suhir's solution of thermal stresses for a die-substrate assembly, ASME Journal of electronic packaging, 126, pp $115-119,2004$

[23]E. H. Wong, K. M. Lim, and Y. W. Mai, Analytical solutions for PCB assembly subjected to mismatched thermal expansion, IEEE Transactions on Advanced Packaging, 22 (3), Aug 2009
[24]E. H. Wong, and Y. W. Mai, Robust design of microelectronics assemblies against mechanical shock, temperature and moisture, Woodhead publishing, Elsevier, 2015

[25]H. Lu, T. Tilford, X. Xue, and C. Bailey, Thermal-mechanical Modelling of Power Electronic Module Packaging, 8th International conference on Thermal, Mechanical, and Multiphysics Simulation and Experiments in Micro-Electronics and Micro-Systems (EuroSimE), Piscataway, NJ, 2007

[26] S. Ganesan, and M. Pecht, Lead-free electronics, John Wiley \& sons, 2006

[27]Z. N. Chang, G. Z. Wang, L. Chen, J. Wilde, K. Becker, Viscoplastic Anand model for solder alloys and its application, Soldering \& surface mount technology, 12 (2), pp $31-36,2000$

[28]J. H. L. Pang (2007) Lead-Free Solder Materials: Design for Reliability. In: E. Suhir E., Y. C. Lee, C. P. Wong (eds) Micro- and OptoElectronic Materials and Structures: Physics, Mechanics, Design, Reliability, Packaging. Springer, Boston, MA

[29]H. Lu and R. Das, Fatigue Damage In Microelectronic Packages, in (edited by A. V. Farahani) Advances in Fatigue, Fracture and Damage Assessment of Materials, 2005

[30]H. Mavoori, J. Chin, S. Vaynman, B. Moran, L. Keer, and M. Fine, Creep, stress relaxation, and plastic deformation in $\mathrm{Sn}-\mathrm{Ag}$ and $\mathrm{Sn}-\mathrm{Zn}$ eutectic solders, Journal of Electronic Materials, 26 (7), pp 783-790, July 1997

[31]R. W. Rohde and J. C. Swearengen, Deformation Modelling Applied to Stress Relaxation of Four Solder Alloys, Journal of Engineering Materials and Technology, 102 (2), pp 207-214, 1980

[32]P. M. Hall, Creep and Stress Relaxation in Solder Joints, In: Lau J.H. (eds) Solder Joint Reliability. Springer, Boston, MA, 1991

[33] A. M. Lush, G. G. Weber, and L. Anand, An implicit time-integration procedure for a set of internal variable constitutive equations for isotropic elasto-viscoplasticity, International journal of plasticity, 5, pp 521 - 549, 1989

[34] G. G. Weber, A. M. Lush, A. Zavaliangos, and L. Anand, An objective time-integration procedure for isotropic rate-independent and ratedependent elastic-plastic constitutive equations, International journal of plasticity, 6, pp $701-744,1990$

[35]J. W. Eaton, D. Bateman, S. Hauberg, R. Wehbring, GNU Octave version 3.8.1 manual: a high-level interactive language for numerical computations. CreateSpace Independent Publishing Platform. ISBN 1441413006, http://www.gnu.org/software/octave/doc/interpreter/, 2014 [36]R. Darveaux, S. Enayet, C. Reichman, C. J. Berry and N. Zafar, Crack initiation and Growth in WLCSP Solder joints, IEEE 61st Electronic Components and Technology Conference, Lake Buena Vista, FL, USA, pp. $940-953,2011$

[37] J. G. J Beijer, M. Y. Jansen, G. M. Jenssen, J. A. Bielen, and E. P. A. Tyssen, Fatigue life of solder bumps in a system in package: relating power cycling to thermal cycling, 7th International Conference on Thermal, Mechanical and Multiphysics Simulations and Experiments in Microelectronics and Micro Systems, EuroSimE, Como, Italy, pp. 1 - 7, 2006

[38]P. Chauhan, M. Osterman, S. W. R. Lee, and M. Pecht, Critical review of the Engelmaier model for solder joint creep fatigue reliability, IEEE Transactions on Components and Packaging Technologies, 32(3), pp. 693 - 700, 2009

[39] H. Lu, C. Bailey, and C. Yin, Design for reliability of power electronics modules, Microelectronics Reliability, 49, pp. 1250-1255, 2009

[40]C. Yin, H. Lu, M. Musallam, C. Bailey, and C. M. A. Johnson, A physics-of-failure based prognostic method for power modules, 10th Electronics Packaging Technology Conference, pp. 1190-1195, 2008 